Supplement of Nat. Hazards Earth Syst. Sci., 18, 1279-1296, 2018

https://doi.org/10.5194/nhess-18-1279-2018-supplement

(C) Author(s) 2018. This work is distributed under

the Creative Commons Attribution 3.0 License.

(c) (1)

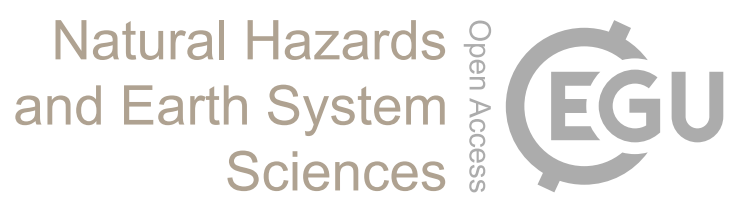

Supplement of

\title{
Assessing floods and droughts in the Mékrou River basin (West Africa): a combined household survey and climatic trends analysis approach
}

Vasileios Markantonis et al.

Correspondence to: Vasileios Markantonis (vmarkantonis@gmail.com)

The copyright of individual parts of the supplement might differ from the CC BY 3.0 License. 


\section{Supplementing Material}

S1. Figure 6: Mean Annual Precipitation, Standard Deviation and Coefficient of Variation (\%) of the entire time series available (CHIRPS 1981-2016), in the Mékrou river basin.

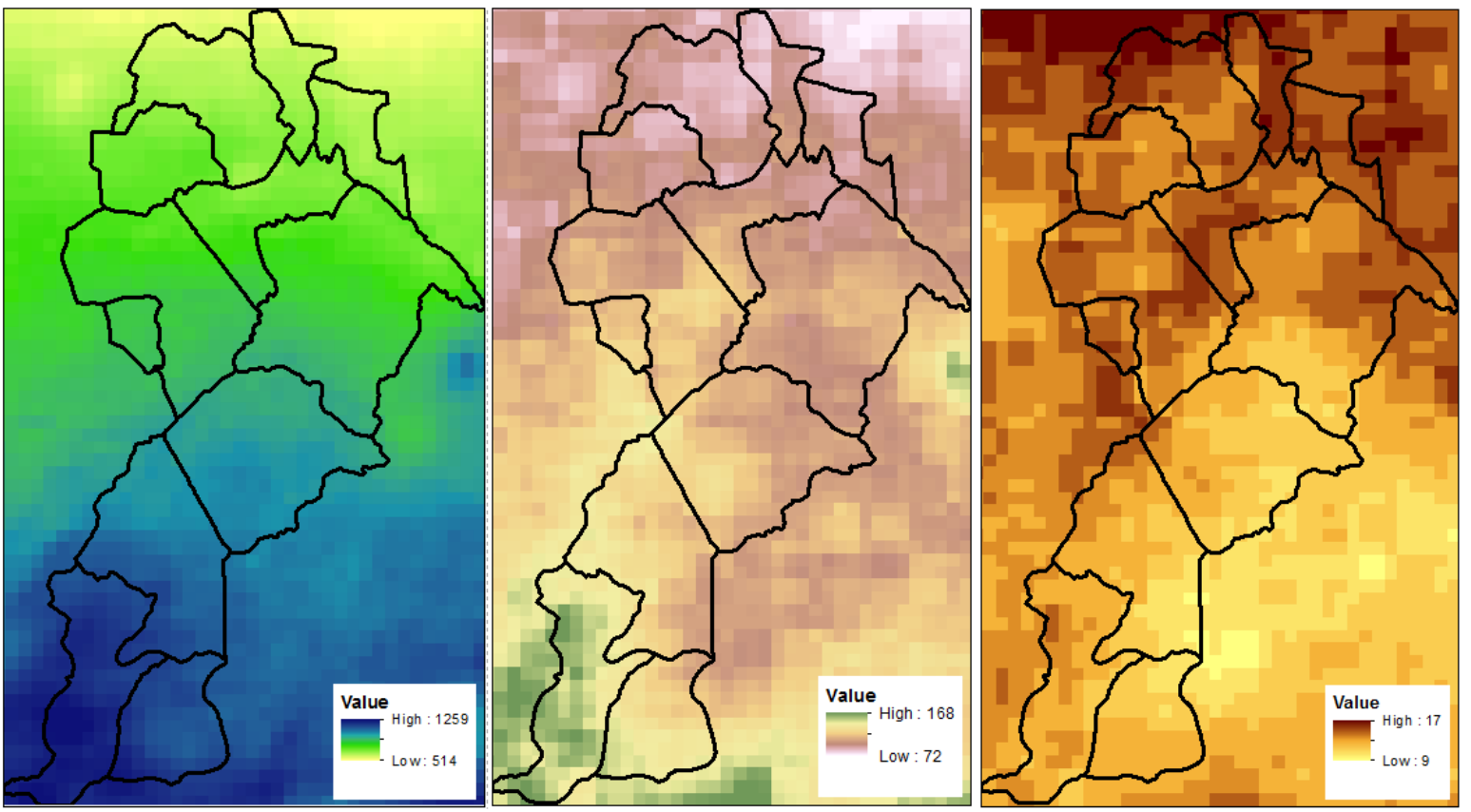

S2. Figure 7: Number of Wet/Dry events per administrative area and SPI type.

\begin{tabular}{|c|c|c|c|c|c|c|c|c|c|c|c|c|c|c|}
\hline & \multicolumn{2}{|c|}{ SPI-3 } & \multicolumn{2}{|c|}{ SPI-6 } & & \multicolumn{2}{|c|}{ SPI-3 } & \multicolumn{2}{|c|}{ SPI-6 } & & \multicolumn{2}{|c|}{ SPI-3 } & \multicolumn{2}{|c|}{ SPI-6 } \\
\hline & W.e & D.e & W.e & D.e & & W.e & D.e & W.e & D.e & & W.e & D.e & W.e & D.e \\
\hline & \multicolumn{4}{|c|}{ Benin } & & \multicolumn{4}{|c|}{ Niger } & & \multicolumn{4}{|c|}{ Burkina Faso } \\
\hline Kouandé & 2 & 1 & 3 & 2 & Park W & 1 & 0 & 0 & 1 & Tansarga & 1 & 0 & 1 & 0 \\
\hline Pehúnco & 2 & 2 & 2 & 2 & Tamou & 2 & 2 & 0 & 2 & Diapaga & 1 & 0 & 1 & 1 \\
\hline Kérou & 2 & 1 & 2 & 1 & Kirtachi & 1 & 2 & 0 & 2 & Bottou & 2 & 0 & 0 & 1 \\
\hline Banikoara & 1 & 3 & 2 & 2 & Falmey & 2 & 2 & 2 & 2 & & & & & \\
\hline Karimama & 1 & 2 & 1 & 1 & Falmey & 2 & 2 & 2 & 2 & & & & & \\
\hline
\end{tabular}


S3. Figure 8: Temporal profile of SPI-3 (JJA) and SPI-6 (AMJJAS). Area percentage per administrative unit affected by different anomaly categories

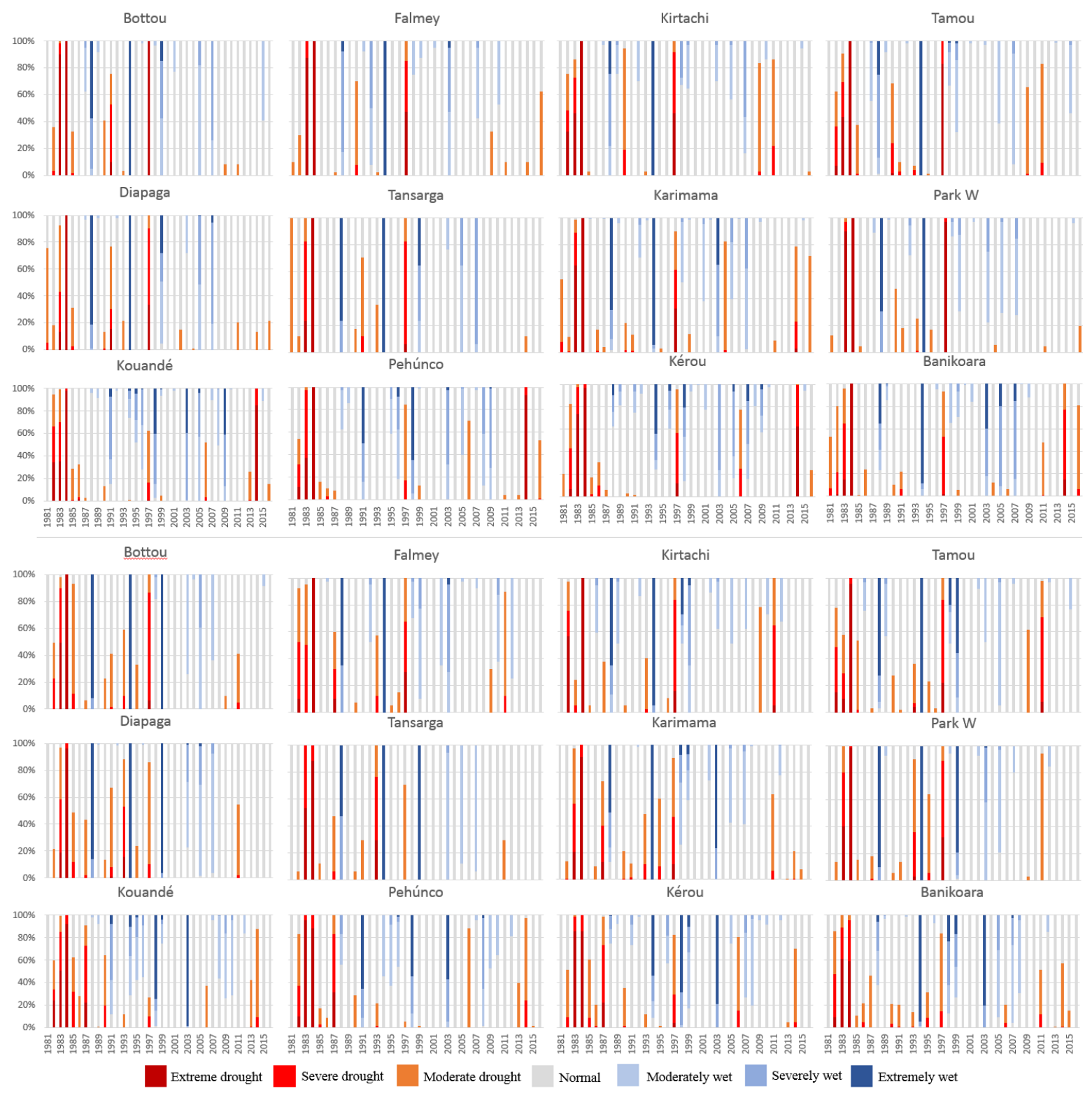


S4: Figure 9: Mean Heat Wave Magnitude Index for the entire Area of Influence and 5-year moving average.

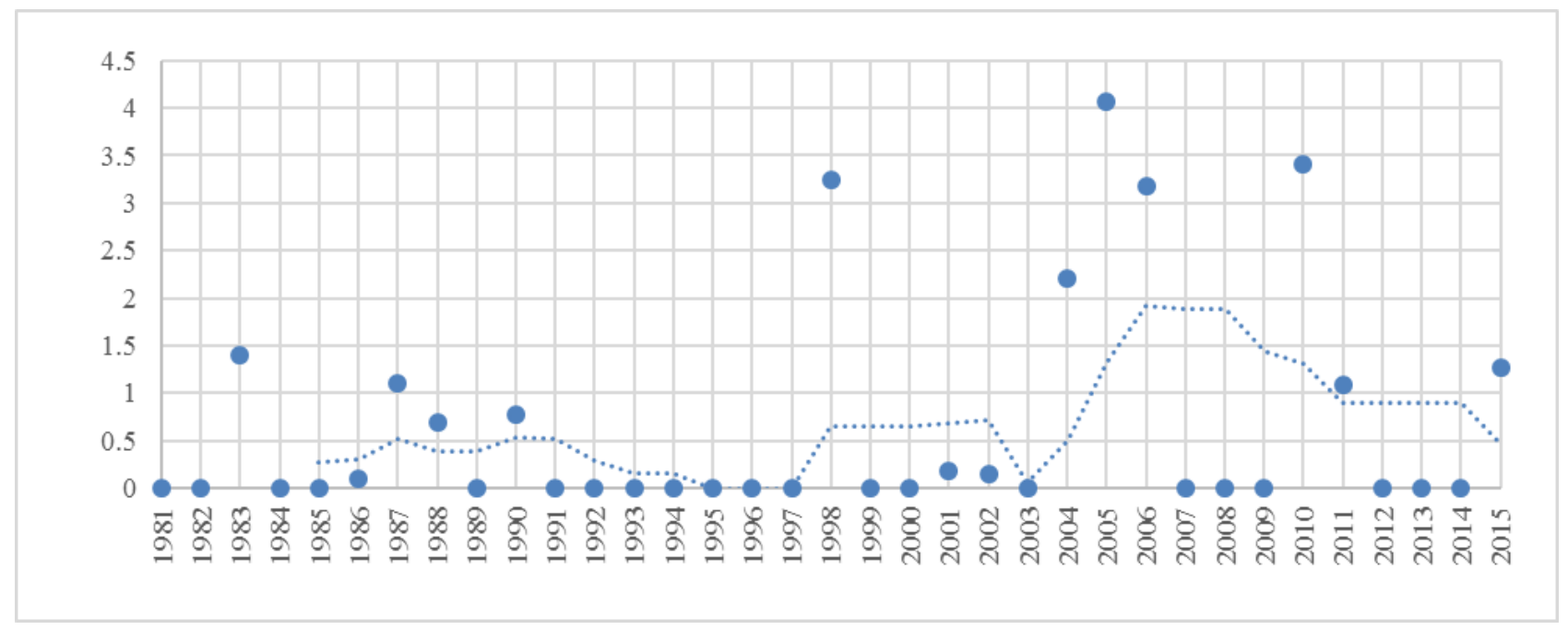

S5: Figure 10: Temporal profile of Heat Wave Magnitude Index per Administrative Area

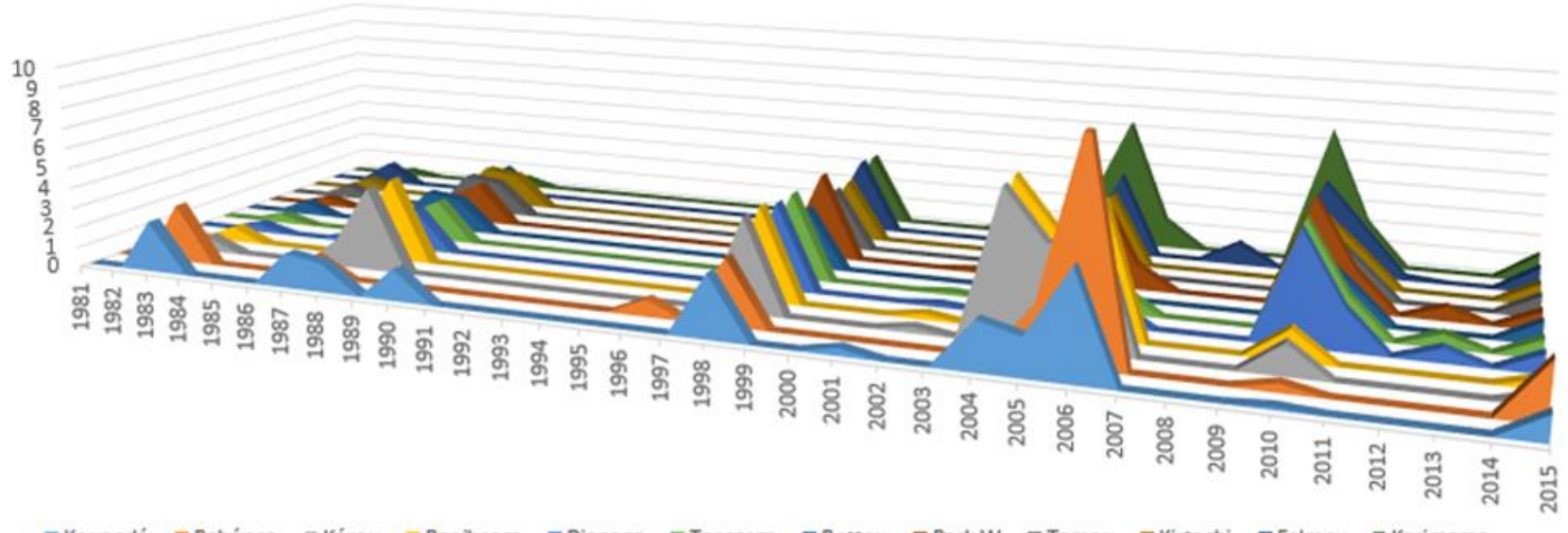


S6. Figure 11: Monthly average discharge at Barou station as modelled in SWAT for the period 19982012; in blue the average; dashed red line is cumulated flow in cubic meter.

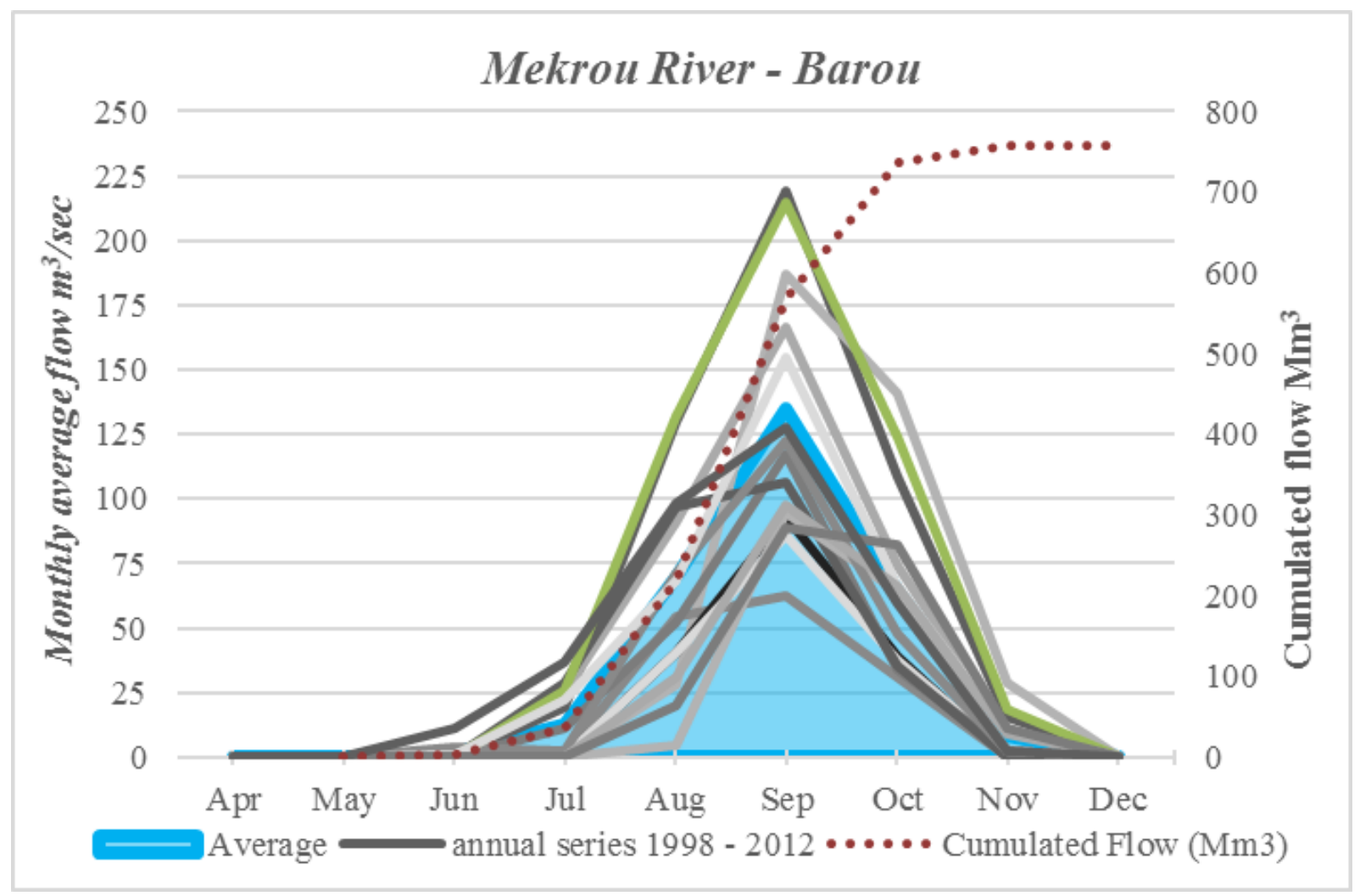


S7. Figure 12: Annual water flow (Mm3) in several subbasin in the Mekrou.

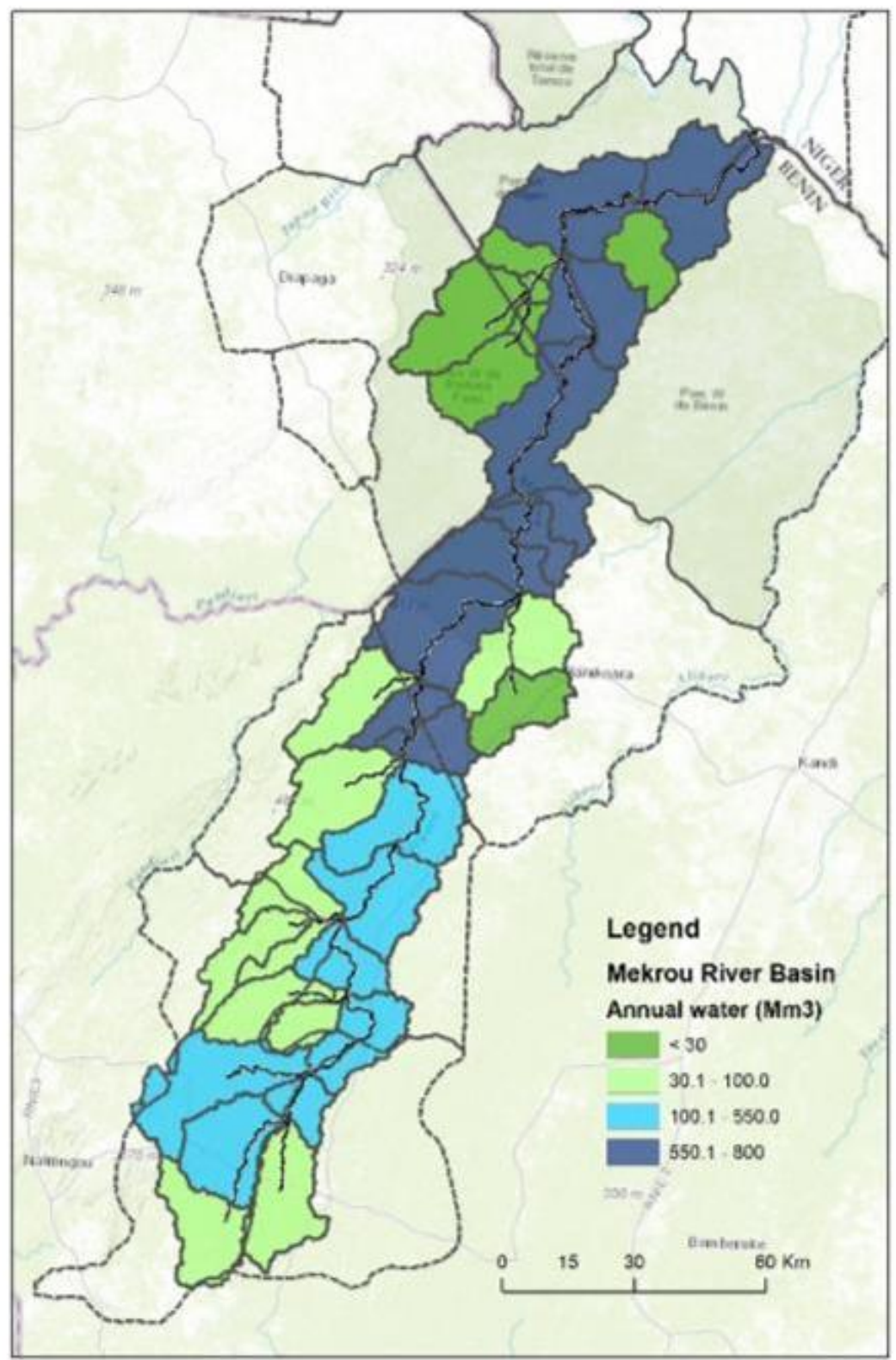

